\title{
Insurance benefits through Indirect investment in Mutual Funds: a case study of Smart Performer
}

\author{
${ }^{1}$ Professor Naila iqbal, ${ }^{2}$ Abhay Arvind Bedekar \\ ${ }^{1}$ Rajiv Gandhi College, Bhopal \\ ${ }^{2}$ Registrar, M P Pharmacy Council, Bhopal
}

Abstract: The Main Objective of this paper is to find out whether one can earn profit while investing in the share market via Mutual Fund and also can have a life cover. The issue of earning profit while investing in the share market via Mutual Fund and also having a life cover is gaining currency now days, in the general mind set of investors and even of the common men.

I. Hypothesis:

Null Hypothesis: H0: There is no significant difference between the performance (Return yielded) of SmartPerformer and its various competitors.

Alternative Hypothesis: H1: H0 is falls.

\section{Methodology:}

Authors first, took a stock of ground realities of same kind of products (which are investing in share markets via MFs and also provide a life cover), collected the data available of the yield of these products and then compared the yield of these products to examine the Null Hypothesis.

III.

About the products:

After searching for the same kind of product in the market, we examined many products of many Life insurance companies like SBIL SmartPerformer, HDFC SL Crest, Reliance Highest NAV Advantage, and Bajaj Max Advantage.

\section{Findings:}

Daily Protect Fund of SBIL SmartPerformer which is the successor of SBIL I AND II is the shining Star among them all. It shows that the average Return provided to the investor by SmartPerformer is in the range of $14 \%$ to $15 \%$ in last 06 months which is the highest among all, with a life cover too.

\section{Conclusion:}

Authors found out that SmartPerformer of SBIL is the product which is providing Maximum Profits as well as Life cover to Its Investors.H0 is rejected.

The Main Objective of this paper is to find out whether one can earn profit while investing in the share market via Mutual Fund and also can have a life cover. The issue of earning profit while investing in the share market via Mutual Fund and also having a life cover is gaining currency now days, in the general mind set of investors and even of the common men.

Also the authors wanted to find out that can "the indirect investments in share market via MF through a medium of Life Insurance" be beneficial for common investors, too.

After searching for this type of product in the market, we assessed many products of many Life insurance companies like:

1) SBIL SmartPerformer,

2) HDFC SL Crest,

3) Reliance Highest NAV Advantage, and

4) Bajaj Max Advantage

Finally we found that the SmartPerformer of SBIL is a product worthy of doing a case study.

Hypothesis:

Null Hypothesis: H0: There is no significant difference between the performances (Return yielded) of SmartPerformer and its various competitors.

Alternative Hypothesis: H1: $\mathrm{H} 0$ is falls 
SMART

\section{About the product}

\section{PERFORMER}

(A unit linked life insurance plan)

SBI Life's 'SBI Life - Smart Performer'(06 Sept 2010 to 28 Feb 2011) is the product of study in this paper. This is a unique Unit Linked, non-participating product that offers the twin benefits of 'Higher than the Highest' of the daily NAV on Maturity Guarantee and the prospect of market upside.

It Provides a Guarantee at Maturity based on the Highest Daily NAV during the first seven years.

It offers - Guarantee and Market Upside through unique Plan offerings of 'Secure Plan' and 'Secure N Grow Plan'.

It has Automatic Rebalancing to lock-in the gains.

It gives Convenience to investors through Single Premium or shorter Premium Paying Term (PPT) of 05 years. It provides Life Insurance Coverage with minimum Sum Assured of 10 or 07 times of the Annual Premium (AP) (based on age) and Liquidity through Partial Withdrawal(s).

It also has an Option to customize the product with Accidental Death Benefit and an excellent Investment cum Insurance plan with attractive Tax Benefits.

SBIL SmartPerformer is split into 04 phases.

1) 'Subscription' phase is for first 06 months period from the launch date, during which new policies will be issued.

2) 'Premium Payment' phase begins from the first premium paid and continues for next 05 years from the end of subscription phase for a Limited Premium Payment Term (LPPT) Option while for a Single Payment the premium shall be paid at inception.

3) 'NAV Built-up' phase lasts for 07 years from the date of launch.

4) 'Accumulation' phase the last 03 years of Policy Term.

The Maturity Date shall be at the end of 10 years from the launch date. The premium contributions, net of Premium Allocation Charges are invested in the Plan Options - 'Secure Plan' or 'Secure N Grow Plan', as chosen by the investor. Under 'Secure N Grow Plan' one continues to enjoy gains through 'Automatic Rebalancing' facility. One also has the choice to have added protection by choosing the Accidental Death Benefit Option. The premium for Accidental Death Benefit will be charged by cancellation of units of one's Funds.

The Guaranteed Maturity NAVs will pertain to the 'Daily Protect Fund' only. The Guaranteed Maturity NAV will be offered by SBI Life which will be $5 \%$ more than highest daily NAVs, recorded during the first 07 years from the date of launch of the product.

The guarantee applies for the enforce policies and is available only at Maturity. For deaths, surrenders and discontinuance the guarantee does not apply. For the amount withdrawn as Partial Withdrawal the guarantee would not apply. However for the remaining units in the Daily Protect Fund the NAV guarantee would apply. On completion of policy Term, Maturity Value will be paid.

Maturity Value for the Daily Protect Fund will be calculated based on NAV which is higher of: a) Prevailing NAV as on Date of Maturity OR

b) Higher than the Highest Guaranteed NAV: There will be an increment of 5\% to the Highest NAV achieved during the first seven years under the 'Daily Protect Fund'. The guarantee will be available only if all the due premiums have been paid.

In addition, if there are any units in the Index Fund, the Fund Value of such units, calculated at the Prevailing NAV would also be added, in order to arrive at the Maturity Value.

The Death Benefit is payable only when policy is enforce.

In case of the unfortunate event of the death of the Life Insured, who is not minor, during the Policy Term, SBIL will pay the higher of Fund Value or Sum Assured subject to a minimum of $105 \%$ of the total premiums paid at the time of death.

In case the Life Insured is a minor, SBIL will pay the higher of Fund Value or Sum Assured3 subject to a minimum of $105 \%$ of the total premiums paid at the time of death. The benefit is payable in lump sum.

SmartPerformer gives the flexibility to withdraw money from the 6th Policy Year onwards or on attainment of age 18 by the Life Assured whichever is later. One can make one Partial Withdrawal per Policy Year, which is free of cost. Subsequent to a Partial Withdrawal at any time during the Policy Term, if the Fund Value is not sufficient to recover the charges, the policy will be terminated immediately and the Fund Value without deduction of any charges will be paid.

All rights and benefits under the policy will automatically cease thereafter. 


\section{Option 1: Secure Plan}

The entire premium (net of allocation charges) paid, is invested in the 'Daily Protect Fund' and one shall get a return based on the performance of this Fund and the underlying guarantee.

\section{Option 2: Secure N Grow Plan}

Out of the entire premium (net of allocation charges) paid, $80 \%$ would be allocated to the Daily Protect Fund and the remaining 20\% would be allocated to the Index Fund, to provide the chance for higher participation in equity. This plan comes with the unique feature of Automatic Rebalancing.

\section{Automatic Rebalancing:}

Given the ups and downs in the market, Automatic Rebalancing facility adds immense value by allowing lock-in to one's gains.

- If the total premiums (net of allocation charges) invested into the Index Fund appreciate by $15 \%$ or more, such gains would be transferred to the Daily Protect Fund. This rebalancing can happen only from the Index Fund to Daily Protect Fund and not vice-versa.

The Automatic Rebalancing facility would not be available after the end of the 6th Policy Year.

\section{Tax Benefit:}

Premium(s) paid under the product are eligible for tax deduction u/s 80C of the Income Tax Act, 1961, provided the total premium during the year does not exceed 20\% of the Sum Assured subject to conditions. The benefits under this plan are tax exempt u/s 10 (10D) of the Income Tax Act, 1961 subject to conditions. Service tax and education cess shall be charged extra as per applicable rates. Please note that all benefits payable under the policy are subject to Tax Laws and other financial enactments as they may exist from time to time.

\section{Free Look Period:}

One can review the terms and conditions of the policy, within 15 days from the date of the receipt of the Policy Document and where he/she disagree with any of those terms and conditions; have the option to return the policy stating the reasons for objection.

The amount refunded would be:

Fund Value + (Premium Allocation Charges + Policy Administration Charges+ Guarantee Charges + Accidental Death Benefit Charges, if any) already deducted MINUS (Stamp Duty + Medical Expenses, if any + Payment Instrument Collection Charges, if any) Mortality charges already deducted will not be refunded.

\section{Grace Period:}

Grace period for this plan is 15 days for monthly mode and for other modes 30 days.

Discontinuance of Premium (Applicable only for LPPT):

On discontinuance of premium, one can either revive the policy or completely withdraw the Funds without any Life Cover by paying the applicable discontinuance charge, if any.

\section{Surrender:}

One can surrender the policy at any time during the Policy Term.

- If surrender is requested during the first 5 Policy Years:-

Then a lock-in condition applies. The Fund Value after deduction of applicable discontinuance charge (if any), will be transferred to the 'Discontinued Policy Fund'. One will earn a minimum interest rate of 3.5\% p.a. on this Fund. No further charges are deducted from the fund. Life cover and Accidental Death Benefit cover (if any) will cease to apply. The Fund Value will be payable on the 1st working day of the 6th Policy Year.

- If the surrender is requested any time after completion of 5th Policy Year then the Fund Value will be paid immediately.

\section{Methodology:}

Authors first, took a stock of ground realities of same kind of products (which are investing in share markets via MFs and also provide a life cover), collected the data available of the yield of these products and then compared the yield of these products to examine the Null Hypothesis. 


\section{Performance of the Product}

The SmartPerformer of SBILife is a unique life insurance product, which is providing very good returns to the customers through the indirect route of investment in Mutual Funds in the Market. The performance (Return Yielded) of SmartPerformer and its various competitors in last 03 and last 06 months is given below:

Table: 01 Performance of Products

\begin{tabular}{|l|l|l|}
\hline Product & Last 3 months & Last 6 months \\
\hline SBIL I & $12.7 \%$ & $15.2 \%$ \\
\hline SBIL II & $14.0 \%$ & $14.6 \%$ \\
\hline Birla Platinum Fund & $13.2 \%$ & $13.9 \%$ \\
\hline LIC Wealth Fund & $\mathbf{0 4 . 5 \%}$ & $\mathbf{0 6 . 5 \%}$ \\
\hline Bajaj Max gain & $\mathbf{0 6 . 3 \%}$ & $\mathbf{0 9 . 4 \%}$ \\
\hline Reliance NAV Guarantee Fund & $\mathbf{0 9 . 7 \%}$ & $\mathbf{0 8 . 0 \%}$ \\
\hline
\end{tabular}

\section{Conclusion:}

After seeing the performance of all these funds we came to the conclusion that the performance of SBIL NAV funds is best among all. Daily Protect Fund of SBIL SmartPerformer which is the successor of SBIL I AND II is the shining Star among them all. It shows that the average Return provided to the investor by SmartPerformer is in the range of $14 \%$ to $15 \%$ in last 06 months which is the highest among all, with a life cover too.

Hence, we can conclude that there is a significant difference between the performance (Return yielded) of SmartPerformer and its various competitors. H0 is rejected.

\section{Bibliography:}

[1] Fisher Donald E and Jordan Ronald J ,'Security Analysis and Portfolio Management", Prentice Hall India, New Delhi,1995,pg658Dave S.A.: Op.cit,2

[2] Pierce ,James L: Monetary and Economics ,John Wiley \& Sons(1984),Pg.81

[3] Weston J Fred and Brigham, Eugene F:Essentials of Managerial Finance, Dryen Press, 2000

[4] The V.N.R. Dictionary of Business and Finance, Van Nostrand,Rein Cold Company, New York,2001

[5] Portfolio Management \& Mutual Fund, ICFAI Publications.

[6] Fund Manager, Aug. 2004

[7] www.valueresearch.com

[8] www.amfiindia.com

[9] www.mutualfundindia.com

\section{Annexure-1}

About the company

SBI Life Insurance Co. Ltd:

SBI Life Insurance is a joint venture between State Bank of India and BNP Paribas Assurance. SBI owns $74 \%$ of the total capital and BNP Paribas Assurance the remaining 26\%. SBI Life Insurance has an authorized capital of Rs. 2,000 Cr and a paid up capital of Rs 1,000 crores. State Bank of India enjoys the largest banking franchise in India. Along with its 05 Associate Banks, State Bank Group has the unrivalled strength of over 16,000 branches across the country, arguably the largest in the world. BNP Paribas, one of the leading banks in Europe, ranks 5th in the banking industry worldwide. It is 06th most valuable international banking brand as per Brand Finance 2008. BNP Paribas Assurance is the insurance arm of BNP Paribas - Euro Zone's leading Bank. BNP Paribas, part of the worlds top 10 groups of banks by market value and part of Europe's top 03 banking companies, is one of the oldest foreign banks with a presence in India dating back to 1860 . BNP Paribas Assurance is the Fourth largest life insurance company in France, and a worldwide leader in Creditor insurance products. SBI Life's mission is to emerge as the leading company offering a comprehensive range of Life Insurance and pension products at competitive prices, ensuring high standards of customer service and world class operating efficiency.

SBI Life has a unique multi-distribution model encompassing vibrant Bancassurance, Retail Agency, Institutional Alliances and Corporate Solutions distribution channels. SBI Life extensively leverages the State Bank Group relationship as a platform for cross-selling insurance products along with its numerous banking product packages such as housing loans and personal loans. SBI's access to over 100 million accounts across the country provides a vibrant base for insurance penetration across every region and economic strata in the country, thus ensuring true financial inclusion. Agency Channel, comprising of the most productive force of over 75,000 Insurance Advisors, offers door to door insurance solutions to customers. 